\title{
EFICÁCIA DA ADMINISTRAÇÃO PÚBLICA: MYPOSIÇÃO DEMOCRÁTICA
}

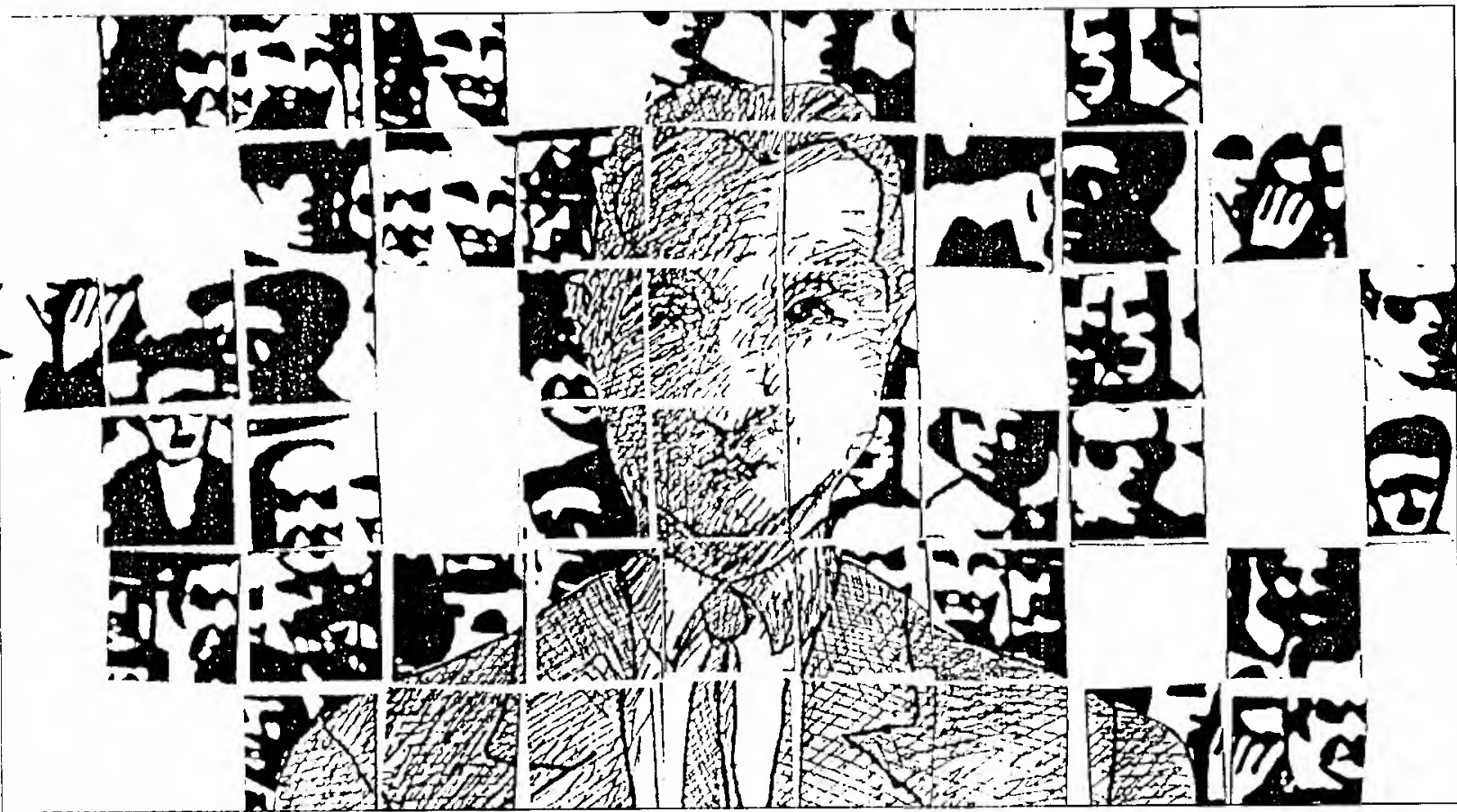

\section{MOEMA MIRANDA DE SIQUEIRA}

Professora Adjunta da UFMG, Bacharel em Sociologia e Política e Administração Pública e Mestre em Administração pela UFMG, doutora em Administração pela USP e pesquisadora do CNPq.

RESLIMO: Este trabalho discute a importância de se aunu'ntar a performance da administração pública como garantia ite conquistas democráticas. Considera a avaliação como $\mathrm{km}$ instrumento valioso para melhoria dos resultados e propöe 1 un inodelo envolvendo três dimensóe's: analítica, buscando compreender as variáveis macro e' microssociais que condicionam o desempenho da adrrinistração pública: instrumental, ajudando o processo de tomada de deisoes; prescritiva, propondo medidas para melhorar as ações, especialmente relacionudas ì sua dermocratizaño.

PALAVRAS-CHAVE: Aaliação da administraçâo puiblica, modelo de avaliaçio, desempenho da administração priblica, denocratizaçio da administração pública.

\section{INTRODUÇÃO}

F m oposição ao caráter "racionalizador" que E envolveu as políticas sociais da primeira fase do governo autoritário brasileiro pós-64, significando primordialmente redução de custos, o discurso e as práticas progressistas estatais desconfiaram durante muito tempo das preocupações ditas "gerenciais".

No entanto, principalmente frente à constatação de que a indiscutível ineficiência da administraçăo pública brasileira tem constituído argumento reforçador dos interesses privatistas, essa postura tem mudado.

Hoje, parece já consensual que os avanços democráticos na área social incorporados à nova Constituição impõem-nos o desafio de estabelecermos uma estratégia de eficiência para o setor público.

Essa estratégia deverá refletir inevitavelmente a dicotomia estrutural do campo da administração pública, e que a diferencia das organizações privadas, implicando, de um lado, em restrições políticas - com questões de poder, confli- 
to e legitimidade - e de outro, em considerar aspectos técnicos específicos de gerência e administração.

A responsabilidade social característica da Administração Pública deve impor-lhe, mais do que às organizações privadas, especialmente em países com escassos recursos como o nosso, compromisso com resultados eficazes da "coisa pública".

Evidentemente, resultados eficazes na administração pública significam democratizar o acesso em todos os níveis; ser permeável ao controle da sociedade; melhorar a qualidade dos serviços prestados e aumentar o grau de resolutividade dos problemas.

Nenhum desses objetivos pode prescindir da avaliação. E o processo de avaliação é, nessas condições, altamente estratégico para a administração e gerenciamento da Administração Pública. Neste momento histórico de grandes dificuldades econômicas, políticas e sociais, se a avaliação é importante para os projetos privados, como instrumento de sobrevivência econômica, para a administração pública ela é elemento de legitimação e suporte à prestação de contas de seu caráter político. $O$ cidadão tem direito ao conhecimento das atividades do Estado e do uso de sua contribuição.

As escassas análises existentes têm focalizado principalmente o processo político de formulação e de tomada de decisões, não aprofundando as suas conseqüências e impactos na sociedade.

Avaliação, no conceito aqui adotado, é uma tarefa que deve perpassar todo o processo de produção social de bens e serviços. Portanto, não apenas ocorre na fase posterior de execução de uma atividade ou projeto, mas tem pelo menos três momentos privilegiados: um na fase inicial, outro na implantação e outro ao final da atividade.

$\mathrm{Na}$ fase inicial do processo, a análise crítica de alternativas, através de uso de índices e coeficientes, é um elemento avaliativo que instrumentaliza a escolha (tomada de decisão) para a alocação de recursos.

$\mathrm{Na}$ fase de implantação dos projetos, a avaliação é um instrumento de acompanhamento, permitindo corrigirem-se as distorções e exigindo periodicidade regular.

Ao final de uma atividade, a avaliação visa a verificar o atendimento aos objetivos e metas préestabelecidas. É a fase por excelência e específica da avaliação.

Evidentemente tais separações são muito mais didáticas que reais. $\mathrm{Na}$ prática, não existe uma clara linha divisória entre formulação/decisão e implementação de projetos. Na medida em que são implementados são também reformulados. $O$ processo não é linear, mas dinâmico e circular.

Como sofremos uma síndrome constante dos "objetivos espetaculares $e$ dos resultados decepcionantes", como fala Pedone ${ }^{1}$, é fundamental e uma exigência democrática que se avalie a administração pública, divulgando-se amplamente os resultados da avaliação.

A tradição burocrática-autoritária dificultou o desenvolvimento de instrumentos e de práticas avaliativas da ação governamental. $O$ planejamento foi pensado autoritariamente, de cima para baixo, centrado exclusivamente no orçamento. Não é sequer normativo, mas apenas explicita procedimentos, como preencher papéis, jamais preocupando-se com a qualidade.

É um desafio democrático a construção de um modelo e de uma estratégia para avaliar a administração pública brasileira.

Supõe a capacidade de saber lidar com a contradição entre tornar menos coercitivo o Estado, diminuindo seus controles e regulações, e aumentar a sua eficiência, implicando em reduzir as incertezas, o que tende à normatização.

\section{O QUE AVALIAR}

$O$ processo de avaliação deve responder a questões econômicas, técnicas, temporais e principalmente políticas.

Em relação aos aspectos econômicos, deve-se avaliar a adequação da escolha e o atendimento dos objetivos, considerando basicamente os custos e os benefícios diretos e indiretos, tanto a preços de mercados, quanto a preços sociais.

Os aspectos técnicos são avaliados levando-se em conta a existência de outras alternativas e o grau de pertinência da opção.

Quanto à temporalidade é importante responder à questão sobre se é este o melhor momento - o mais oportuno - para a atividade.

Por fim, a avaliação política é a mais importante, na medida em que responde não só quem foi beneficiado e prejudicado por aquela atividade, mas porque se deu dessa forma, quais os valores envolvidos. A avaliação política supera os modelos de avaliação que se restringem à preocupação com os aspectos formais da atividade governamental dentro do processo político visível e que não questionam o impacto que os programas têm nos problemas e no povo. As análises convencionais são imobilizantes, mantendo o status quo, e

1. PEDONE, Luiz. Formulação, implementaçāo e avaliaçāo de políticas públicas. Brasília, FUNCEP, 1986. 
restritivas em relação a uma maior democratização do processo de formulação e tomada de decisão das políticas públicas.

$O$ enfoque político que aqui se defende deve incluir uma análise responsável e crítica da administração pública, avançando tanto na compreensão das necessidades sociais imediatas como nos reflexos das ações sobre possibilidades de mudança política e social, contribuindo ainda para a avaliação crítica do sistema político como um todo.

A visâo do usuário, a ótica do consumidor, é um dos elementos importantes dessa análise, ajudando na definição dos valores fundamentais do sistema político e da sociedade. Apenas não deve ser considerada como única ou principal fonte, sob o risco de mascarar as explicações mais profundas das percepções $e$ aspirações dos grupos sociais.

Portanto, o que se pretende é a avaliação dos impactos das políticas pública, das mudanças por elas geradas nos grupos-alvo específicos e na sociedade como um todo.
Os valores sociais básicos, a ideologia e as estruturas e práticas do sistema econômico (relações de produção) são categorias básicas dessa análise, na qual as ações governamentais são variável dependente. Mas, numa visão complementar, o estudo dos impactos das políticas públicas quer esclarecer seus reflexos, e as mudanças provocadas, colocando preocupações redistribuitivas como prescrições e posicionando o analista como um "crítico social"2.

\section{DIMENSÃO INSTRUMENTAL DA AVALIAÇÃO}

A avaliação econômica da administração pública envolve a comparação dos recursos consumidos pelas atividades (custos) com os resultados obtidos (benefícios). $O$ diagrama 1 mostra os diferentes enfoques dessa avaliação.

2. Idem, ibidem.

DIAGRAMA 1

DIMENSÃO INSTRUMENTAL DA AVALIAÇÃO

\begin{tabular}{|c|c|c|c|}
\hline $\begin{array}{l}\text { Critérios } \\
\text { Características }\end{array}$ & Eficiência & Eficácia & Efetividade \\
\hline 1. Conceito & $\begin{array}{l}\text { Rendimento } \\
\text { Técnico e/ou } \\
\text { Administrativo } \\
\text { Uso "Ótimo" } \\
\text { de Recursos }\end{array}$ & $\begin{array}{l}\text { Alcance } \\
\text { Objetivos } \\
\text { Previstos } \\
\text { Atividades }\end{array}$ & $\begin{array}{l}\text { Impactos } \\
\text { Diretos + } \\
\text { Indiretos }\end{array}$ \\
\hline 2. Índice/Taxa & Custo/Benefício & Custo/Eficácia & Custo/Efetividade \\
\hline \multirow[b]{3}{*}{ 3. Método de cálculo } & Custos & Custos & Valores \\
\hline & \multirow[t]{2}{*}{ Benefício } & \multirow[t]{2}{*}{ Benefício } & $\begin{array}{l}\text { Numéricos } \\
\text { dos ônus }\end{array}$ \\
\hline & & & $\begin{array}{l}\text { Valores } \\
\text { Numéricos } \\
\text { dos Benefícios }\end{array}$ \\
\hline 4. Fonte dos Dados & $\begin{array}{l}\text { Preços de } \\
\text { Mercado }\end{array}$ & $\begin{array}{l}\text { Preços } \\
\text { Sociais }\end{array}$ & $\begin{array}{l}\text { Valores } \\
\text { Sociais }\end{array}$ \\
\hline 5. Regra Decisória & $\begin{array}{l}B S L>O \\
\text { ou }>B S L\end{array}$ & $\begin{array}{l}\text { Relatividade } \\
\text { F (Variáveis } \\
\text { Críticas) }\end{array}$ & $\begin{array}{l}\text { Política - } \\
\text { Impacto } \\
\text { Social }\end{array}$ \\
\hline $\begin{array}{l}\text { 6. Instrumento de Coleta } \\
\text { de dados }\end{array}$ & $\begin{array}{l}\text { Planilha de } \\
\text { Custos }\end{array}$ & $\begin{array}{l}\text { Planilha de Custos } \\
\text { + Matriz de } \\
\text { Relevância }\end{array}$ & $\begin{array}{l}\text { Planilha de Custos } \\
\text { + Matriz de } \\
\text { Relevância }\end{array}$ \\
\hline
\end{tabular}


A análise de custo/benefício determina o benefício social líquido de uma atividade, a preços de mercado, e sua regra decisória é bem clara: somente se o benefício social líquido de um projeto for maior que zero ele deverá ser implementado. Se há alternativas múltiplas com escalas comparáveis, a melhor será aquela que apresentar o maior Benefício Social Líquido (BSL). O indicador obtido é o da eficiência, entendido como o rendimento técnico e/ou administrativo, voltado para o uso "ótimo" de recursos.

O resultado da Análise de Custo/Benefício (ACB) são expressos em unidades, como dólares por cliente tratado ou cruzados por aluno alfabetizado. É, portanto, muito útil na comparação de programas ou atividades alternativas cujos efeitos podem ser medidos com as mesmas unidades.

Uma técnica complementar é a análise de custoeficácia. Trata-se de uma forma especial de análise de custo-eficiência cuja medida dos custos e dos benefícios é feita a preços sociais.

A medição dos custos e benefícios engloba os gastos associados a uma atividade corrigidos para valores sociais.

A regra decisória da relatividade é um bom subsídio à avaliação da eficácia, relacionando a opção a variáveis críticas, segundo critérios de espaço, tempo e valores culturais.

Quanto à temporalidade, a regra da oportunidade deixa claro que o serviço público será tão mais oportuno quanto se observa a penetração de seus resultados no tempo e no espaço.

Os benefícios também podem ser expressos em unidades e corrigidos para o valor presente. Por exemplo, em estudos de avaliação do tratamento de pacientes renais crônicos, a sobrevida de 20 anos para pacientes em diálise é considerada como benefício. Usando a qualidade de vida desses pacientes como uma medida adicional de benefício, os estudiosos encontram novos valores.

No exemplo citado, da doença renal, Gudex ${ }^{3}$ usou uma classificação de estágios mórbidos desenvolvidos por Rosser \& $\mathrm{Kind}^{4}$ e revista por Williams ${ }^{5}$ para estimar a qualidade de vida.Essa escala trabalha com o valor " $\mathrm{O}$ " para a morte $\mathrm{e}$ " 1 " para a saúde, utilizando comparações entre os valores de qualidade de vida associados aos diferentes estágios de saúde. São requeridas duas medidas de qualidade de vida:

a) incapacidade física e social (mobilidade; interferência com o emprego; trabalho doméstico);

b) Stress (dor; estado emocional; satisfação com a vida).

Resumindo, os critérios mais usuais da avaliação econômica são os relacionados com a eficiência e a eficácia da ação, propondo-se aqui o critério adicional de efetividade, como visualizado no diagrama 1.

São critérios de eficiência aqueles relativos ao rendimento técnico e administrativo da ação: o uso ótimo dos recursos alocados (financeiro, material, $\mathrm{RH}$ ou tempo), padrões de qualidade dos resultados; a capacidade para atender à demanda etc.

A avaliação política, apesar das dificuldades de sua efetivação, é o item mais significativo da análise da efetividade.

A resposta à indagação sobre se os serviços públicos estão sendo ou não compativeis com os postulados democráticos é neste momento o cerne da avaliação política. E deve discutir em que consiste democratizar os serviços e quais os instrumentos capazes de promover a equalização de oportunidades.

Para Hirschmann ${ }^{6}$, existe um mecanismo alternativo ao de mercado para aumentar a eficiência da administração pública que são a voz e o protesto do público diretamente interessado em seu desempenho.

Nesse sentido, embora nem sempre identificado como alvo direto da mobilização coletiva, o Estado estaria funcionando como propulsor de movimentos sociais, principalmente e em decorrência de sua omissão na oferta de bens públicos?

A já clássica análise de Castells ${ }^{8}$ sobre os movimentos urbanos, a partir da problemática da crise da cidade capitalista, acredita num processo crescente de politização do cotidiano em virtude da ação contraditória do Estado. Os serviços coletivos são indispensáveis ao modo de vida suscitado pelo desenvolvimento capitalista, mas não são

3. GUDEX, Claire. "Qualys and their use by the health service". In: Discussion Paper, no 20, Center for Health Economics, University of York, 1986.

4. ROSSER, R. \& KIND, P. "A scale of valuation of states of ilness: is there a social consensus?"In: International Journal of Epidemiology, vol. 7, $\mathrm{n}^{\mathrm{0}}$ 4, pp.347-358, 1978.

5. WILlIAMS, Adams. "Economic of coronary artery by pass grafting". In: British Medical Journal, $\mathrm{n}^{\mathrm{o}}$ 291, 1985, pp. 325-329.

6. HIRSCHMAN, Alberto. De Consumidor a cidadão. São Paulo, Brasiliense, 1983.

7. JACOBI, Pedro R. “Movimentos sociais - teoria e prática em questão". In: SCHERER-WARREN \& KRISCHKE, Paulo J.(orgs.). Uma revolução no cotidiano? Os novos movimentos sociais na América Latina. São Paulo, Brasiliense, 1987.

8. CASTELLS, Manuel F. Cidade, democracia e socialismo. Rio de Janeiro, Paz e Terra, 1980. 


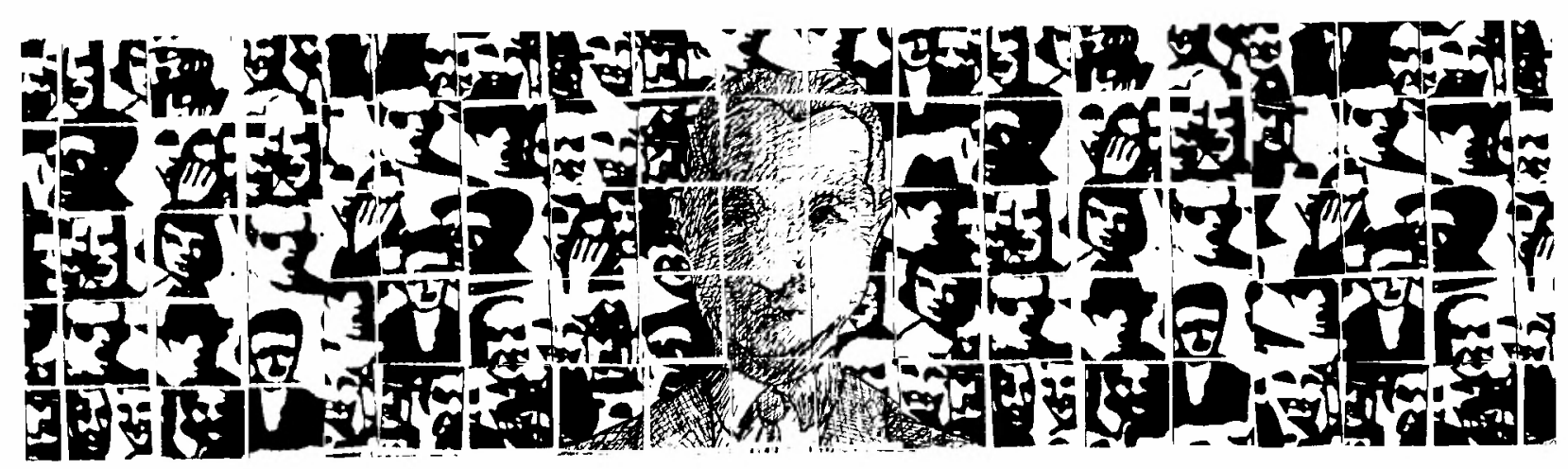

suficientemente rentáveis para estimularem os empresários privados à sula produção. Com isso, segundo Castells", amplos setores da população, e não necessariamente da classe operária tradicional, se unem e se articulanı en defesa de modos de vida ameaçados pela voracidade do capital.

As análises mais radicais desse processo enfatizam uma excessiva polariyação das relações Estado/movimentos sociais, chegando a falar em contracriaçöes populares.

Pelo menos para a América Latina e para o Brasil, de modo particular, essa última não parece a análise mais adequada, considerando-se que a maioria dos movimentos demanda algum tipo de intervenção do Estado na solução de seus problemas ${ }^{10}$. Se de um lado os movimentos redescobrem novas formas de açào e participação, o Estado também anplia seu espaço e modifica sua dinâmica de interação ${ }^{31}$. Os interesses não homogêneos mas contraditórios das lasses dominantes explicariam () caráter frequientemente ambíguo das intervençóes do Estado como representante hegemônico daqueles interesses.

A identificação e a análise dos movimentos sociais são, portanto, um instrumento fundamental da avaliação política da administração pública, ao lado da visão do usuário. Esta deverá, necessariamente, incluir os valores, a ideologia e a estrutura e práticas do sistema de produção, envolvendo variáveis de nível simbólico.

Sugerent-se os levantamentos da percepção sobre o papel do Estado (missão), democratização, equiidade e eficiencia, entre outros valores.

No levantamento da percepção do usuário, é prudente relembrar uma ressalva de Thiollent ${ }^{12}$ sobre a tendéncia a se confirmarem os valores da classe dominante mesino entre membros da classe operária, quando entrevistados em situações rotineiras, demonstrando a extensão do processo de alienaçào.

Resta detalhar-se aqui a maneira de se avaliaren os impactos da atividade governamental.

Frequèentemente, a avaliação, quando ultrapassa o nível dos inpuls (recursos), permanece no nível do processo (como são as atividades realizadas), raramente concentrando-se nos efeitos e principalmente nos impactos. Impactos no sentido aqui adotado são algo mais que os efeitos individuais, considerando-se a indução de efeitos em cadeia (favoráveis ou desfaroráveis) dentro da sociedade. A premissa da postura valorativa e prescritiva do modelo aqui proposto fornece o elemento comparativo básico para a avaliação do conteúdo. $O$ padrão geral será a democratização do acesso aos bens e serviços públicos.

Qualquer pais que pretenda ser politicamente democrático deve democratizar o acesso aos bens e serviços, especialmente os de consumo coletivo.

A matriz de relevância de variáveis, proposta por Baptista ${ }^{13}$ pode ser um excelente auxílio na avaliação de impacto.

Um exemplo do uso dessa matriz é apresentado no diagrama 2 .

A lista de variáveis aqui escolhida, evidentemente, í exemplificativa, devendo-se, para cada caso, identificar aquelas mais significativas.

O modo de utilizar a matriz é explicado pela autora a partir da ponderação de cada variável listada nas linhas e consideradas como causa em relação a seus efeitos sobre aquelas colocadas nas colunas. A ponderação variará de $0=$ nenhum efeito a 4 = efeitos fortíssimos. Preenchido o quadro, a somatória das linhas representará a dimensão da variável como efeito no contexto analisado. Para maior objetividade das ponderações, devem-se

\section{Idem, ibidem.}

10. $\mathrm{BOSCl}-\mathrm{Il}$, Renato. Movimentos sociais e institucionalização d' wma ordem. Nova Friburgo, ANPOCS, 1984.

\section{J ACOOBI, Pedro R. Op. cit.}

12. THIOLLENT, Michel. Crítica metodológica, investiga ģãa social e enquéte operária. São Paulo, Polis, 1980.

13. BAPTISTA, Myrian V. Planejamento: introdução à metodologia de plmejinminto social. São Paulo, Moraes, 1981. 
utilizar indicadores consagrados relativos às variáveis como fontes das análises e, principalmente, usar grupos de avaliadores ao invés da avaliação exclusiva do técnico. A participação dos usuários constitui importante subsídio nessa tarefa.

Pelo exposto, conclui-se que não são poucos os problemas para a montagem de um modelo de avaliação da administração pública. Dentre eles, destacam-se:

- a precariedade dos processos científicos e metodológicos de mensuração de dados, principalmente de natureza qualitativa;

- a limitação dos referenciais teóricos convencionais em relação à capacidade explicativa das

\section{DIAGRAMA 2}

\section{MATRIZ PARA ANÁLISE DE RELEVÂNCIA UM EXEMPLO: DEMOCRATIZAÇẤO DA SAÚDE}

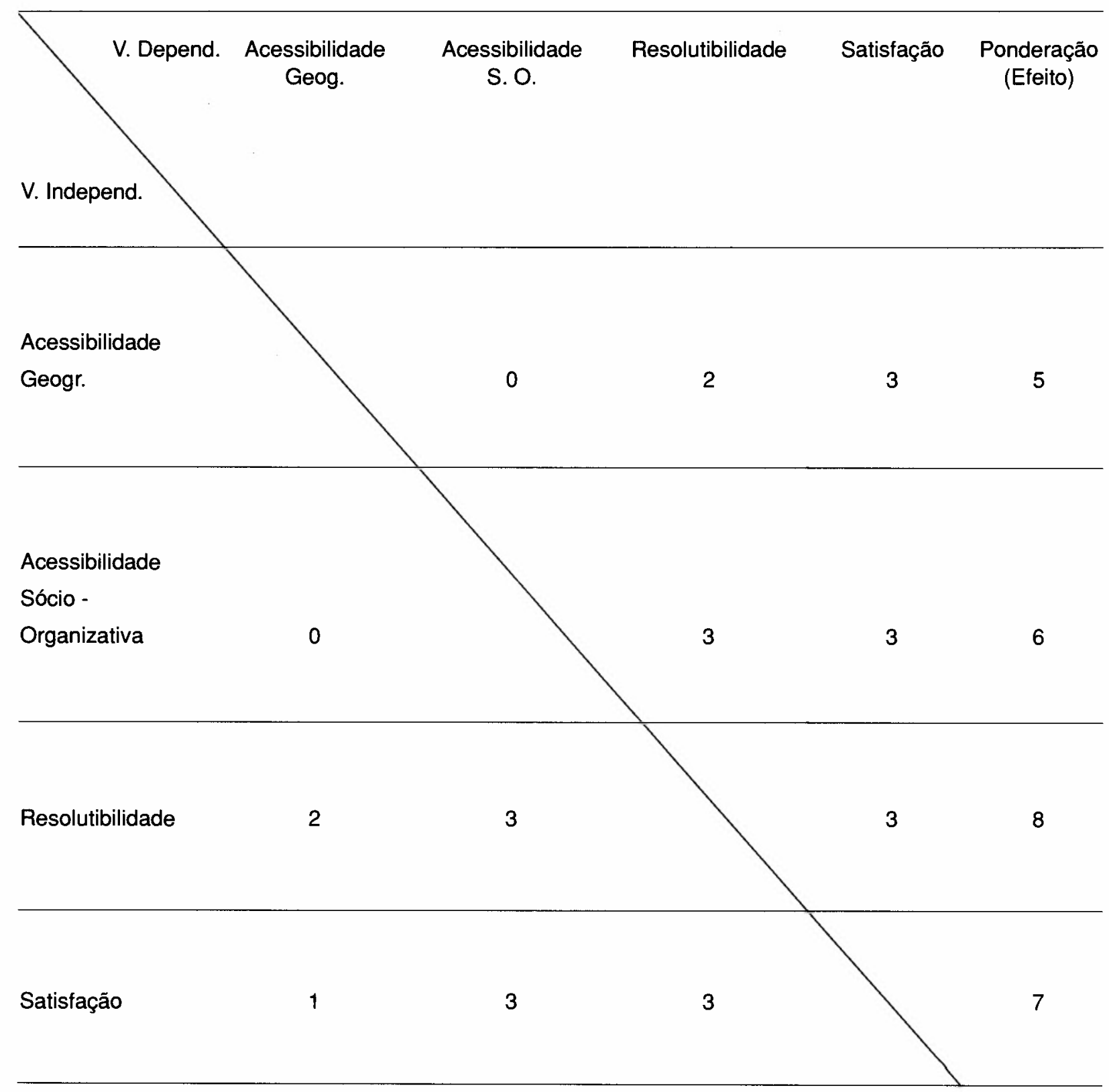




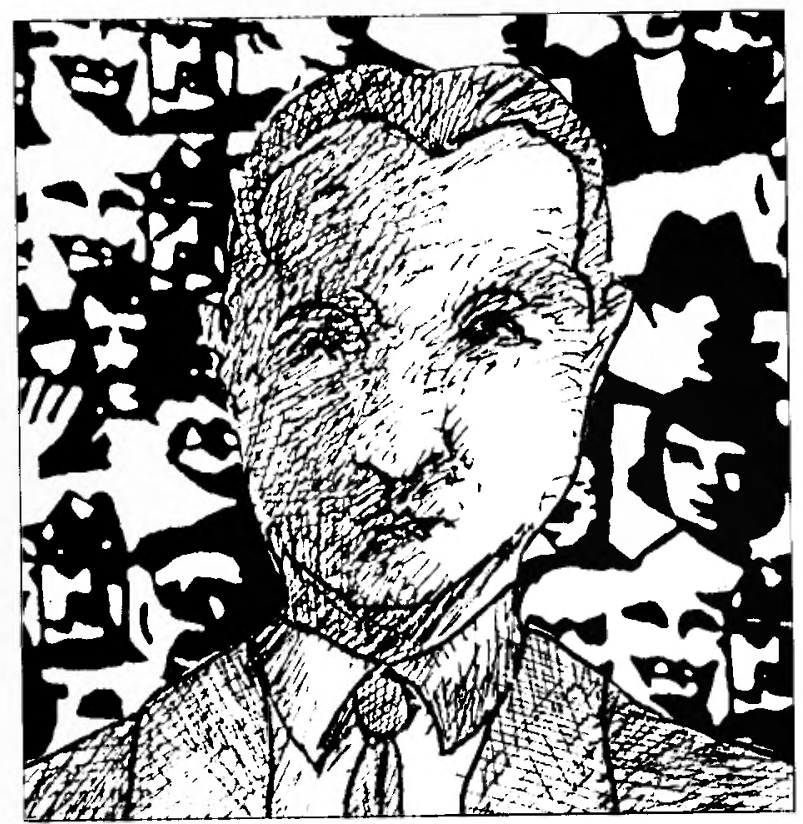

dimensões macrossociais;

- a dificuldade para estabelecer relações entre indicadores, especialmente dos impactos das ações governamentais.

Essas dificuldades, no entanto, não podem ser justificativa, como querem alguns, para o abandono da a valiação da administração pública.

Ela é um dos principais desafios democráticos de nosso tempo, principalmente nos países com escassez de recursos como o Brasil.

Uma das caracteristicas intrínsecas do capitalismo contemporâneo é que ele expandiu e tornou mais abrangente 0 controle do Estado e da grande empresa oligopolista, crescentemente internacionalizada, sobre os processos econômicos e as relaçōes sociais. No Brasil, a expansão das atividades estatais fez-se acompanhar por um verdadeiro processo de "privatização" do Estado através da apropriação por grupos privados da Res Pública ${ }^{14}$.

A herança formalista e corporativista foi reforçada amplamente no período autoritário por estratégias de comando unitário e de controle central.

Dessa forma, a luta para construção de uma ordem que garanta os direitos básicos do cidadão passa necessariamente pelo estabelecimento $e$ alargamento do controle coletivo sobre as decisões fundamentais da sociedade, concentradas hoje na esfera estatal e na da iniciativa privada.

A questão fundamental, portanto, reside no maior controle coletivo sobre decisões fundamentais para a sociedade.

Uma das características diferenciadoras mais importantes entre "empresa pública" e "empresa privada" é justamente o controle público, entendido como algo bem mais abrangente que controle governamental. Controle público implica na responsabilidade da ação governamental perante o poder Legislativo, Judiciário (tribunais), grupos de consumidores, organizações sindicais e outras organizações de trabalhadores, movimentos sociais e outros tipos de agências não governamentais.

Em virtude da tradição histórica brasileira de autoritarismo e elitismo político, fundamentada em características semelhantes das relações entre indivíduos e grupos sociais, a tendência passada foi pouca participação e um alto grau de consenso, reproduzindo o caráter hierárquico das relações sociais.

As elites, com alta capacidade de expandirem o sistema, mantinham fechadas as possibilidades de participação dos setores populares e cooptavam os grupos emergentes.

Os movimentos sociais da década de 70 são vistos como resultantes do esforço de se criarem novos canais de expressão num contexto de repressão e bloqueio até mesmo dos escassos instrumentos de participação tradicional ${ }^{15}$.

Eles poderão contribuir para a indispensável criação e consolidação de mecanismos democráticos que garantam a participação da sociedade nas decisões do governo e o acompanhamento e controle dos resultados da administração pública.

A avaliação nesse processo é um instrumento estratégico e o modelo aqui proposto pretende contribuir nas seguintes dimensões:

a) dimensão analítica - Capacidade de compreender as variáveis, tanto de natureza macrossocial quanto microssocial, que condicionam o desempenho da administração pública e o papel dos diferentes atores nesse processo.

b) dimensão instrumental - Capacidade de ajudar a tomada de decisão frente a diferentes alternativas, de acompanhar o desempenho dos serviços públicos e de avaliar e divulgar seus resultados.

c) dimensão prescritiva - Propor medidas de melhoria das ações governamentais, especialmente relacionadas à sua democratização crescente.

Essas dimensões não são excludentes, mas complementares, como visualizado no diagrama 3.

14. MARTINS, Luciano. Estado capitalista e burocracia no Brasil pós 64. Rio de Janeiro, Paz e terra, 1986.

15. POMPERMAYER, Malori J. et alii. Movimentos sociais em Minas Gerais: emergência e perspectivas. Belo Horizonte, UFMG, 1987. 
DIAGRAMA 3

\begin{tabular}{|c|c|c|}
\hline \multicolumn{3}{|c|}{1 - DIMENSÃO ANALÍTICA } \\
\hline \multicolumn{3}{|c|}{ ANÁLISE POLÍTICA } \\
\hline & Nível Macro & Nível Micro \\
\hline & - Relaçōes de Produção & - Configuração organizacional \\
\hline Atores & - Governo & - Jogos específicos do poder \\
\hline & - Burocracia & - Poder decisório da organização \\
\hline & - Cidadão & - Usuário/contribuinte \\
\hline \multirow[t]{2}{*}{ Valores } & \multirow{2}{*}{$\begin{array}{l}\text { - Postulados Democráticos } \\
\text { - Direitos sociais }\end{array}$} & - Participação \\
\hline & & - Reivindicaçōes \\
\hline \multicolumn{3}{|c|}{2 - DIMENSĀO INSTRUMENTAL } \\
\hline \multicolumn{3}{|c|}{ ANÁLISE ECONÓMICA } \\
\hline Fontes & \multicolumn{2}{|l|}{ Critérios } \\
\hline Preços de mercado & \multicolumn{2}{|l|}{ Eficiência } \\
\hline Preços sociais & \multicolumn{2}{|l|}{ Eficácia } \\
\hline Valores sociais (intangíveis) & \multicolumn{2}{|l|}{ Efetividade } \\
\hline \multicolumn{3}{|c|}{3 - DIMENSĀO PRESCRITIVA } \\
\hline \multicolumn{3}{|c|}{ ANÁLISE ÉTICA } \\
\hline Fontes & \multicolumn{2}{|c|}{ Prescrições } \\
\hline Valores Democráticos & \multicolumn{2}{|c|}{ Transparência das decisões } \\
\hline Princípios participativos & \multicolumn{2}{|c|}{ Canais de participação } \\
\hline Ideal de bem-estar & \multicolumn{2}{|c|}{ Qualidade de vida } \\
\hline
\end{tabular}

ABSTRACT: The present study discusses the need of increasing public administration efficiency in order to guarantee democratic gains. It considers the evaluation process a privileged instrument for getting better results while presenting a model of three dimensions:

a) analytic, which searches for the understanding of both the macrosocial and microsocial variables that influence public administration performance; b) instrumental, which facilitates the decision-making process;

c) prescriptive, which proposes actions that aim the achievement of better results, specially in the field of democratization.

KEY TERMS: Public services evaluation, public administration performance, evaluation model, democratization of public administration. 